\section{THE VALUES OF SCIENCE TO HUMANITY*}

\author{
By PROF. A. G. TANSLEY, F.R.S.
}

$\mathrm{T}$ O most people to-day the word science suggests, first of all, the marvellous modern applications of science to human use. Such inventions, yearly increasing in numbers and in scope, have enriched human life not only on its material side, but also indirectly, in æsthetic, intellectual and spiritual aspects. By quickening every sort of intercommunication they have put the most widely separated products of human thought and creativeness at the disposal of everyone. By 'annihilating time and space', as the vivid phrase goes, they have drawn the peoples of the world together.

It is tragically true, of course, that scientific inventions have also placed enormous means at the disposal of those men of evil will who have seized power in their own countries and have taken advantage of the deficiencies of international organization to disrupt and overwhelm neighbouring States. Shallow and thoughtless critics have blamed science and men of science for these catastrophes. They should rather have blamed man's failure to develop an adequate ethical standard in international rela. tions, his failure to acquire that sense of human solidarity with which the race can no longer dispense if it is to survive under tolerable conditions. Not science but lack of morality is the culprit. Man's material power has altogether outrun his ethical development. It is as impossible to check scientific discovery and its application to human purposes as to stop an inflowing tide. What those purposes shall be must depend on the degree of man's spiritual development, on the values in which he really believes.

The primary motive that prompts a man to learn and practise science is the desire to obtain organized knowledge of the objective world around him. Such knowledge may be sought for its own sake or for its practical usefulness. When the former motive is predominant we have been accustomed to speak of 'pure science', as contrasted with 'applied science' when scientific knowledge and scientific method are used for the solution of practical problems of human life. The devising, improvement and elaboration of technical methods of dealing with materials and processes for practical ends may best be called 'technology'. But we are told by an increasingly vocal school of scientists turned publicists that there is no real distinction between pure science and technology, that the root of man's interest in knowledge of the natural world is the use he can make of it, and that pure science is either the theoretical formulation of knowledge originally sought for purely practical ends or, when it is not this, a form of recreation which is at best harmless if it does not divert attention from more serious and useful pursuits.

The essence of science is said to be the acquirement of power over Nature. Science has been actually defined as "the system of behaviour by which man acquires mastery of his environment". We had supposed, until we were thus instructed, that science meant a kind of knowledge, not a kind of behaviour. Indeed the most elementary thinking about the human mind and human activity would seem to

* Extracts from the Herbert Spencer Lecture delivered in the University of Oxford on June 2, 1942. The complete lecture is pub. lished by George Allen and Unwin, T.td., 18 . Cd. net. require a primary distinction between knowing and behaving.

But if we pass over this extraordinary misuse of ordinary language we are confronted with two contradictory views of the status and function of science -on one side the view that science is a body of knowledge primarily concerned with the effort to satisfy human needs, 'pure' science, so far as it may be entitled to recognition at all, being an offshoot, so to speak, of this body of knowledge; and, on the other hand, the view that pure science is a primary body of knowledge and theory, which has no necessary relation to practical needs, but much of which may be applied to those needs with far-reaching effects. What is the explanation of this contradiction? I think it may be found in the confusion of historical and psychological points of view. Historically, pure science may fairly be said to 'emerge from' a body of knowledge much of which is empirical and technological. Psychologically, pure science, as it exists to-day, has a completely independent status, and incidentally is the source of all significant technological advance. Let us consider this matter in some little detail.

That the kind of knowledge we call science leads directly to increased power over Nature, that it is the source of our wide and powerful modern control over the materials and forces of the external world, is obvious to all. Primitive man got the first glimmerings of the foundation of scientific knowledgethat similar causes produce similar effects-in the conditions of his hard daily struggle to maintain himself and perpetuate his race in a hostile or at best an indifferent world. Such knowledge was purely empirical knowledge. Fire burns, but it will also cook food and scare off wild beasts; water drowns, but it also quenches thirst ; sharp flints can be used as weapons and also as tools, and so on. Empirical knowledge is not science though it is the indispensable basis of science. A good many writers are in the habit of using the words 'science' and 'scientific' for all knowledge gained by primitive man, and in the earlier civilizations, about his material environment, simply because it related to the objects and processes which now form the subject-matter of branches of science such as physics, chemistry, geology and biology. Most of this knowledge was purely empirical. Science does not come into existence until some kind of generalization is formed in the mind, a generalization that can prove its validity when it is applied to new phenomena.

The transition from purely empirical knowledge to the first rudiments of scientific knowledge was no doubt an imperceptible transition. We do not know and can never know the times and places and ways in which the first ideas which can properly be called scientific arose out of the bodies of empirical knowledge. We shall be safe in giving the first place to the general notion of causation, an essentially abstract conception which underlies all the rest. The causal nexus between happenings could not fail to impress itself on the primitive human being experiencing the events of his daily life. That $B$ happened because $A$ had happened must have been a very early thought.

There is no evidence and no likelihood that the basic mental equipment of primitive man-at least of men of our own species from Upper Palæolithic times-was substantially different from our own; but he was without our heritage of knowledge. He had to begin from the beginning, from the platform of adaptive instincts built up by and inherited from 
his sub-human ancestors. But he had in supreme degree the power of adaptation and intelligent modification of those instincts to new conditions of life, and with the acquirement of the power of articulate speech he could initiate an oral tradition of knowledge. Thus bodies of traditional knowledge were established, handed on, and gradually increased from generation to generation, varying according to the different environments in which different human groups found themselves. These bodies of empirical knowledge necessarily related primarily to the vital needs of the group, and so it has been throughout the hundreds of millennia of man's history. Equally in pre-glacial times, when man first began to emerge from among his ape-like ancestors and in our twentieth century of the Christian era, equally in London and in Timbuktu, the individual must acquire the knowledge immediately necessary to his continued existence, however widely different the content of that knowledge may be.

So it is also with the aggregate knowledge of a particular human group or community. Those communities which had acquired the particular type and degree of knowledge and skill best adapted to their particular environment were the most likely to survive; and when they came into competition or open conflict with others, those communities would win whose knowledge, skill and material equipment best fitted them for success in the struggle, because the environment of each community included the incidence of its competitors.

How far did primitive man seek objective knowledge of Nature for its own sake, besides acquiring the knowledge essential to his existence ? That, of course, we can never know with any approach to certainty. But it is significant that unspoiled savages to-day show at least as much interest in natural phenomena which do not affect their material interests as does the man in the street of a community which is called civilized. Since curiosity is certainly a primitive human instinct, and it leads to the acquirement of knowledge which is independent of practical usefulness, we can scarcely doubt that such knowledge was sought from a very early period of human history. But pure science cannot attain any considerable development in a society with little leisure. Where the conditions of life are so hard that everyone is almost wholly occupied in keeping body and soul together there is no time or mental energy available for the acquirement and organization of much knowledge for its own sake. In such conditions the great bulk of the knowledge that is acquired is practical knowledge, how to secure and extend control over that part of the environment which is of immediate practical significance, and then to make life easier and more comfortable. Thus arose the arts of foodgathering, of hunting and fishing, of stone implement making, of the taming and training of animals, of primitive agriculture, of weaving and pottery making, of building and primitive metallurgy. Chance observations, hit and miss experiments, the use of experience and primitive inductions, must have been the means employed. The improvement and elaboration of these various arts were the foundations of technology.

With the attainment of settled conditions and the advancement of technology, surplus wealth, that is, stocks of commodities not required for immediate use or consumption, could be accumulated, trade could develop, comfort could be increased, and eventually the luxury created which has been so marked a feature of the more elaborate civilizations. At the same time leisure became more abundant, at least for some members of the community. The arts of writing and of calculation were invented, and geometry and astronomy began to emerge as coherent bodies of knowledge. Practical needs such as trade, craftsmanship and the making of calendars were no doubt the immediate stimuli to these developments; but since we have every reason to believe that the mental constitution of the races which have occupied the Near East and Europe during the last four thousand years has been essentially constant throughout, it is impossible to doubt that the satisfaction in discovering new knowledge for its own sake, which is the driving force of research in pure science, must have been present in those early civilizations of the great river valleys of the Near and Middle East just as it was probably present in much earlier savage ancestors.

From at least the sixteenth or seventeenth century onwards there has been a body of scientific knowledge and theory which had continuity, and each generation could build upon the foundations laid by its predecessors. Discovery in science, hitherto isolated and sporadic, became a continuous process, and thus pure science, cultivated for its own sake, acquired an independent life. Needless to say, it was often influenced in volume and direction by social and economic as well as by intellectual conditions, and it often took technical problems as starting-points. But it was never wholly determined by such influences, and a great deal of it was undertaken with no reference whatever to the usefulness of its results. It is such research, in fact, that has ultimately led to the most striking practical discoveries and inventions. It is a striking fact that many discoveries made in the course of work undertaken with no practical aims have unexpectedly turned out to be keys to important applications of science in wholly different spheres. As scientific knowledge and theory become increasingly complex all sorts of cross-connexions between different departments reveal themselves, new branches arise, occupying hitherto unexplored ground between the older fields, and others cut across the old boundaries and take their material from several such fields. For this reason alone-the unexpectedness of discoveries and the unexpectedness of their applications-it would be disastrous to attempt the direction of all research to specific practical objects or to hamper complete freedom of investigation.

At the same time we must recognize that a good deal of work in pure science is unlikely ever to be of any practical use, though it may be of the greatest interest. Such, for example, is the detailed history of the earth, of its rocks, its vegetation and its animal life, and also a great deal of the detailed morphology of the plant and animal kingdoms. Should we discourage such work or deny it the necessary facilities? There are at least two good reasons why we should do nothing of the kind. In the first place we could never safely draw the line between work which might prove materially useful and work which certainly never would. If we once began to draw such distinctions we should put science into the power of those who clamour for results of immediate practical use and have no understanding of the complex and vital inter-relations of its different parts. The second reason goes much deeper, though it is connected with the first. Any such restriction of research would deny the right of 
men of science to investigate and increase our knowledge of the whole phenomenal world, and the right of the individual man of science to choose the field which his abilities and inclinations best fit him to explore.

The immense and complex development of pure science has the most far-reaching applications to human activity and profound effects on technology. Separating out, as we have seen, from the undifferentiated body of scientific discovery and technological invention of a former age, and acquiring an independent life of its own, pure science became the main source of all fundamental technological advance, while its full potentialities of application to other fields of human life are just beginning to be realized.

Historically, then, scientific theory arose piecemeal in one field and another, emerging from the growing structure of practical empirical knowledge or from the independent study of Nature. Gradually the separate pieces coalesced and began to form coherent bodies of theoretical knowledge. As it became securely established the structure of scientific theory acquired an independent existence and its description as 'pure science' became justified. On every hand it fertilized technology and made possible great advances and entirely new developments in the most various technological fields. Thus the term 'applied science' began to be used for the applications of pure science to the practical purposes of human life. Once established as an independent human activity, pure science assumed a continuity and a universal status which technology can never have, simply because all but the most elementary material human needs are partial and variable, so that human arts and crafts and manufactures rise and fall, appear and disappear, while organized knowledge of the world of Nature is permanent and free from such fluctuating conditions.

Technology is essentially 'patchy': technological research is occupied in solving unrelated practical problems of technique in the most various fields of human activity. Deeper penetration to underlying causes is not, as a rule, any concern of the technologist. All he cares about, as a technologist, is the solution of his immediate problem. The pure scientist, on the other hand, is perpetually seeking underlying causes, relations between things previously unsuspected of being related. This constant search is the essence of pure science, and when it succeeds great new fields are often opened up for exploitation by the technologist.

Recent writers who have envisaged not only technological but all scientific work as a "social activity' determined by current social conditions and directed to the satisfaction of current social needs, have had no difficulty in demonstrating the general correlation of work that may be described as scientific with social structure and social requirements at various times and places. But to justify their sweeping conclusions they have had to lump together the whole body of empirical, technological and pure scientific knowledge of Nature and of human arts and crafts acquired throughout the ages; and they have misrepresented with a strange perversity the real nature and the essential psychology of scientific research. Up to the seventeenth century research for the sake of pure knowledge was on the whole sporadic, and the great bulk of the work described as determined by social conditions was technological work, though great scientific discoveries and generalizations were made here and there. Since then, as pure scientific work began to coalesce and acquire continuity, the determination of its direction by purely social factors has become less and less marked.

Leaving now the historical development of science we turn to the essential psychology of scientific work of various kinds.

No one contends that scientific men who engage in research are entirely uninfluenced by the social conditions of their time or by the particular conditions of their own early life and environment. It is obvious enough that these conditions must have a great effect on the formation of the scientist's mind and therefore on all his activities. The individual human mind has a certain specific hereditary endowment, but it does not work in vacuo. The material with which it is fed in childhood and youth and the influence of its particular environment must play a large part in determining its future activity.

The actual motives, both conscious and unconscious, which may cause a man to-day to embrace a scientific career of any sort are various and of different orders; the same, of course, may be said of any other human activity. For the vast majority there is the over-riding necessity of earning a living, and the particular work or career adopted will obviously depend on opportunities and prospects. A century ago a 'career' in science was open only to a very few. To-day opportunities are numerous and increasing, owing partly to the rapid growth and development of pure science but mainly to the enormous extensions of applied science and technology. The great majority of these openings lead only to laboratory posts the duties of which are those of what is sometimes called 'routine research', that is, to the making of tests, trials and checks on the instructions of a superior. A smaller but still a considerable number of posts are available in teams of research workers in industrial or Government laboratories engaged on the attempted solution of technical problems or sometimes of problems in pure science which are thought to have a direct or at least an indirect bearing on technical progress. This again is 'directed' work, just as much as that of a clerk in an office, though its intrinsic interest to the scientifically minded may well be much greater. To a few comes the possibility of promotion to the position of a subordinate director of the technical work of others or to the headship of a research team, and a very few may become directors of scientific departments or institutions where they will have much more opportunity of initiative, though very commonly such appointments are not made from the personnel of the particular laboratory, but often go to people from outside with a different sort of training. It is obvious, then, that to the vast majority of 'scientific workers' only technological work in which there is little freedom or opportunity for initiative is available.

There remains the possibility of employment in the teaching of science as a schoolmaster or at a university. A few schoolmasters find time and inclination for independent research, but the conditions are not often favourable. On the other hand, academic science teaching is usually combined with research and most of the current research in pure science is actually done at universities, much of it by university teachers.

Probably most of those who adopt one or other of these scientific careers-certainly those who enter the last-named-in order to earn a living have to a greater or lesser degree what is called the 'scientific bent'. This shows itself either as a strong interest in 
and desire to obtain organized knowledge of the natural environment-more often of some particular part of it, such as stars, rocks, animals, or plants-or as a specific interest in 'how things work' commonly seen in a small boy's keenness to find out how a machine is constructed and how its parts act.

What are the psychological factors underlying the 'scientific bent'? 'Curiosity' is the most general concept under which the first impulse to both kinds of scientific interest-in environment and in working mechanism-may be brought. Curiosity has been defined as "the desire or inclination to learn or know about anything, especially what is novel or strange". This is the adult expression of the curiosity which may fairly be regarded as a primary instinct of many higher animals, and is conspicuously displayed by human beings from a very early age. The human infant expresses it by making sensory contacts with the unfamiliar objects of its immediate environment, through sight, smell, taste, touch and manipulation. This is the primitive means of 'getting into touch with' or acquiring knowledge of one's surroundings.

The promiscuous curiosity of the young child, if it is not smothered by overwhelming repression but is controlled and canalized by the direction of intelligence, under the influence of growing experience, develops into the desire for organized knowledge of the objective world around him. This may take either or both of the two forms we have already distinguished, leading to interest in the 'natural history' sciences or in what has been called "general analytical science". Much can be learned from books and from oral teaching, but the unblunted instinct can be directly satisfied only by independent observation and experiment. It is the satisfaction by talented people of the desire for organized knowledge of the objective world that has gradually built up the permanent structure of pure science by successive descriptions and discoveries and by the conceptual welding of these into coherent bodies of scientific theory, the parts of which are constantly modified or replaced as fresh discoveries are made or deeper insight gained into the relations of phenomena.

The consistent object of pure scientific research is to establish a coherent body of objective knowledge and explanatory theory over the whole range of natural phenomena. In the course of this work new phenomena come to light, often by chance, and some of these can be exploited industrially. At the same time new principles are established which give rational direction and lead to crucial improvements in industrial processes that had hitherto been purely empirical. It is naturally physics and chemistry that have had the most extensive use in the field of technology, because industrial processes deal mainly with dead material. But biology has made important contributions to the two great practical arts of medicine and agriculture, and we are now on the verge of far-reaching social developments in which the applications of biological and psychological knowledge will play a commanding part.

We must not underrate the scientific importance of the enormous amount of work that is now done in technological laboratories attached to industrial firms, instituted or assisted by Government, and sometimes attached to universities. Not only is it necessary to improve and perfect established industrial processes and to learn how to exploit new scientific discoveries on an industrial scale, but also in the course of such work new scientific problems emerge which have to be solved if further advances are to be made. Some of these problems can be tackled in the technological laboratory itself, others are remitted to laboratories of pure science. Some technical laboratories, indeed, though founded solely for work in applied science, do in fact spend part of their time in pure scientific research on problems chosen from the particular field. Thus pure science and technology act and interact to the advantage of both, and so it must always be. While insisting on the essential distinction between them, we must not forget that the two are in one sense parts of a whole - a whole which has a fundamental unity given by the consistent application of the scientific method to every sort of problem, whatever the material and whatever the object. But the immediate object, which carries with it the specific motive, does determine the nature and scope of the results.

We have defined pure scientific investigation as the pursuit for its own sake of coherent knowledge of the phenomenal world, and the essence of its being is psychological. The motive actually at work here is nothing else than scientific curiosity, the satisfaction of which is the discovery of new objective truth-of new facts which can be fitted into the framework of pre-existing theory, which require its modifications or restatement, or which demand new theoretical formulations. Technological research has other primary motives. It is always concerned with the solution of a problem for practical purposes. Behind it may lie the motive of making increased profits, or the motives of saving labour, of curing or preventing disease, or of promoting the health and well-being of the population. Several different motives of this kind may be involved at one and the same time, but they are all concerned with direct practical ends.

We must recognize that human motives are often, if not generally, mixed. A man may want to benefit humanity and at the same time to increase his income, and the two very different impulses may be served by the same action. He may also at the same time be moved by genuine curiosity about the solution of his practical problem and experience the joy of discovery when he is successful. The professional scientist, entirely devoted to his research with the unique object of discovering new fragments of truth, cannot ignore the necessity of earming his living. If he were no longer paid he would have to find other employment. But these facts do not affect the truth that the structure of pure science has been built up by men who sought knowledge for its own sake without regard to practical ends, and the further truth that without their work modern technology would never have been possible. If the disinterested pursuit of knowledge were to cease, the structure of science would cease to grow and the springs of all fundamental advance in technology would be dried up. That is one reason why we must uphold the claim of free research in pure science to an assured place in our society.

But it is by no means the only one. Science is indispensable to our complicated material civiliza. tion : it has also intellectual, ethical, rsthetic, and ultimately spiritual values of a high order. In the first place, its constant touch with the world of external Nature in which laws are at work that are uninfluenced by the vain imaginings of human beings keeps our feet on the ground, and should help to check the constant human tendency to fly off into ideological fantasies and to imagine that subjectively constructed and emotionally abiased ideal schemes 
can without more ado be successfully applied to the real world-a tendency responsible for a large number of disastrous political mistakes. I am far from contending that objective sanity is the monopoly of men of science. On the contrary, there is unfortunately abundant evidence that employment in scientific work and even distinction in research is no assured safeguard against domination by misleading idealisms. But there can be no doubt that the scientific habit of mind, with its insistence on preliminary careful and accurate survey of facts and its constant testing of theory by fresh observations and experiments, is the master key to the devising of successful techniques not only in the material but also in the social and political spheres.

One of the best hopes for the future welfare of humanity is the beginning of unbiased investigation of social facts, of social psychology as well as what may be called social anatomy and physiology, and the influence upon these of economic and other environmental factors. The great man after whom these lectures are named clearly saw, sixty years ago, that we needed a real science of society which he proposed to call 'sociology', but it is only recently that the study has begun to assume a genuinely scientific character. Its development is seriously hampered because its field is also an arena of the strongest human prejudices and passions, as the older sciences are not. For many of us an impartial consideration of the facts revealed is very difficult indeed, because our feelings and our private interests are too deeply involved. Ideological constructions, of which the Fascist and the Communist theories of the State are current examples, gain numerous adherents because they satisfy certain human ideals and seem to provide remedies for current evils. In some countries they have been imposed by force, since they also serve the interests of ambitious individuals, Behind a façade of pseudo-philosophy or pseudo-science are concealed gross inconsistencies and often gross cruelties. Yet we must recognize that aspects of sociological truth inhere in the most extreme social and political theories, or they would not appeal, as they do appeal, to so many people of goodwill. For it must never be forgotten that every social theory that appeals to people of goodwill contains at least some element which corresponds with a deep-seated social need, however far it is from being acceptable at its face value.

It is the business of the new scientific sociologist to evaluate these elements in the light of social and individual psychology, as well as to accumulate, marshal, and determine the significance of the widest range of sociological, economic and political facts. It is the ultimate business of our statesmen to implement their mature conclusions. Statecraft, like agriculture and medicine, is a very ancient art, and on one side it must always remain an art. Human beings cannot be managed entirely by text-book rules, however good the text-books. But just as agriculture and medicine have beoome and are still becoming, to their immense benefit, increasingly scientific, by the discovery of the laws underlying the processes involved in the growth of crops and in the human body in health and disease, so the organization and management of human populations, which is the concern of statecraft in its widest sense, can be made increasingly seientific by the proper use of sociological and economic data. The making and still more the application of sociological generalizations demand bold constructive imagination but at the same time the greatest caution and the coolest judgment, precisely because they are so easily influenced and distorted by our prejudices and passions. A certain amount of 'flair', of empirical procedure, and of trial and error experiment are necessary, just as they still are in agriculture and medicine.

We may well ask whether our statesmen are sufficiently equipped for their part of this task, whether their prevailing mentality is of the kind which can freely accept the scientific method and apply it to their problems, whether they are not too hopelessly biased by so-called vested interests, of cless, party, or money. This is indeed a very serious question. Ministers and high officials are constantly betraying their indifference to, or their distrust of, the scientific approach to practical problems, even in such matters as agriculture and food values, in which it is clear that only responsible scientists who have made the relevant investigations have any right to an opinion. It is often only under the stress of war conditions that far-reaching changes are made which have long been urgently required and strongly advocated by all informed opinion.

I am not suggesting that these things can be made right by putting scientists into ministerial offices. The professional scientist is no better fitted than any other professional man to deal successfully with affairs, to excel in administration, or to manage human beings. Indeed if he has become eminent in some particular specialized branch of science it is likely that absorption in his subject will have rather secluded him from those contacts with the world which are desirable if not necessary for a successful administrator. Nor would it meet the case to require every prospective minister and public official of high rank to take a course in elementary science! It is not specialized scientific knowledge that is wanted here, but the scientific spirit, an intelligent appreciation of what science really is and what it can do. We may acknowledge that the habit of consulting experts has increased of late years. But in the modern State with its innumerable problems demanding scientific knowledge and investigation, the scientific approach should be a matter of course, and the existing temper of Government and official circles is generally averse from such an approach.

A glaring example is the treatment of agriculture in Great Britain by successive Governments since the War of 1914-18. The basic cure for the ills of British agriculture has been and is the scientific approach to its problems combined with a statesmanlike comprehension of the part the land should play in the national economy not only in producing food, but also in keeping a substantial and contented fraction of the population in contact with the fruitful earth. It is of no use to keep juggling with prices and quotas, or to keep changing the Minister. What is wanted is a man of wide outlook and scientific imagination, who has a general knowledge of the advances that have been made in agricultural research, a readiness to take into his intimate counsels the men who really understand them in detail, and the courage and drive to pusti through the necessary comprehensive plans. Some part of the appropriate measures have been taken in response to the urgent needs of war-time for an increased native food supply, but they cover only part of the field, and we should like to be sure that they will not be discontinued as soon as peace is proclaimed.

What is needed is a complete change of heart, and 
it does not seem that this can be brought about except by a change in education. The current education of the men who are entrusted with the forming of Government policies has almost wholly ignored and frequently despised science. Though giving a grudging recognition to its contribution to their material amenities, many of these men regard science with a mixture of dislike and fear-dislike because it seems to them hostile to the traditional cultural values they accept, fear because they are apprehensive that its tendency is to destroy those values. I am not one of those who depreciate classical or historical education. I should look with alarm at the prospect of severance of our culture from its historical roots-the philosophy, literature and art of Greece and Rome-or from the historical channels through which it has developed. But there is no reason whatever why a liberal education in the old sense should not be extended to include a sound introduction to scientific culture. Time could be found by reshaping the curricula and omitting the unessential. I contend that education cannot justly be called liberal to-day unless it includes an introduction to science and the history of science, simply because science is a vital part of the culture fitted to the contemporary world.

The reformed liberal education that $I$ have in mind must begin in the secondary if not in the elementary school. It should be the normal school curriculum and in the hands of teachers thoroughly imbued with its spirit and significance. It has nothing to do with so-called 'specialization' in science, which at present begins at too early an age and may easily have a narrowing effect on the mind, as can unfortunately be seen in many scientists and technologists who have specialized too early and who tend to despise the other disciplines. Narrowness of cultural outlook is not, however, confined to scientific men. I have heard in this University of Oxford historians and others who are supposed to have had a liberal education express almost incredibly narrow and short-sighted views about the place of science in education.

We have just been considering the essential importance of science and the scientific spirit in the economy and service of the State. But the reorientation of education I have advocated would do far more than produce a new and better type of minister and high official. It would broaden and vivify the minds of all who experienced it, at least of those at all able to benefit by a liberal education. Equally with literature and art, science has its own contribution to make to the development of the mind, its own distinctive quality engendered by the habit of dispassionate objective investigation and of respect for objective truth. The scientific mentality forbids the unconditional acceptance of views and formulæe represented as authoritative but often motived by traditional bias or by selfish interest. It teaches humility and submission to the logic of established facts, and counteracts the arrogance of human prejudice and wilfulness. This is an ethical as well as an intellectual contribution. I do not contend, of cuurse, that this particular moral quality is confined to men of science; only that it is an essential part of the spirit of science and that the wider diffusion of that spirit will powerfully aid the growth of the virtue.

Finally there is the rsthetic aspect of science, which opens the mind to a far deeper and wider realization of the wonder and beauty of the universe.
This is not a trivial claim though it may seem to some old-fashioned. A real and deep rsthetic satis. faction is brought by the constant contemplation of the infinite beauty of Nature, ranging from the galaxies of astronomical space through the marvellous diversity of scenery and of the living beings inhabiting the earth's surface, to the fascinating world revealed by the microscope and the still more minute phenomena dealt with by structural chemistry and intraatomic physics. The gradual discovery of these things and of the laws which explain their relations, constantly reformulated and made to fit the observed phenomena ever more closely, is indeed a marvellous and majestic story, a story in which the human spirit can find refreshment and escape from the conflicts and tragedies of human life just as it can find escape and refreshment in the finest literature and the greatest music. The very impersonality of the subject-matter of science makes the refuge particularly complete. I recall that the group of men who afterwards founded the Royal Society sought refuge in the peaceful atmosphere of their experiments and discussions from the increasing political tension of London during the conflict between king and parliament. If the fashionable and facile charge of advocating 'escapism' is brought against me, I can only reply that the possibility of 'escape' in this sense is absolutely necessary to mental health and stability in the modern world.

Scientific culture, then, must take its place on equal terms beside the literary and artistic cultures. Entirely apart from its indispensability for the material comfort and the safety and health of modern urban populations, science has intellectual, ethical and esthetic claims of a very high order. Its achievements are particularly characteristic of our own age. During the last half-century Europe has not produeed poets or musicians who can compare with Shakespeare or Goethe, with Beethoven or Mozart, but it has produced several men whose discoveries are equal to the greatest in the history of science and very many of conspicuous talent, though not of genius, who have contributed between them a much larger body of sound scientific work than has been produced in any comparable period of history. Why then, we naturally ask, is science regarded with dislike and distrust by too many cultivated people who are supposed to have had a liberal education, and by the great majority of the population as a rather mysterious, esoteric agency which produces all sorts of marvellous mechanical contrivances but in which they have no part or lot? It is, I think, because scientific education has been kept in watertight compartments and almost exclusive stress has been laid on its material achievements to the neglect of its cultural values.

It may be objected that it would be impossible to give the masses of the population a liberal education in science, that science for the vast majority can never mean more than technical training in some particular branch that is materially useful. But if the hopes of progressive educationists are realized the aim of the future must be to put a liberal education within reach of everyone. It is my contention that a liberal education in any full and worthy sense must include a broad introduction to science, along with the other elements of knowledge and training which develop the mind, widen and deepen its scope, and do all that education ean do to produce citizens equal to the opportunities and responsibilities of the future. It is perfectly true that only a minority of 
pupils will ever profit at all fully from such an education. A process of sifting must take place in the elementary school and in the secondary school, and only a small proportion of pupils will reach the university. Such a process exists now, though it is very imperfect: in the future we must give the fullest opportunities to all, irrespective of means or social class; but selection corresponding with ability and natural endowment there must always be. It is also clear that specialized training for the work of adult life is necessary, that it must be widely different according to the opening for different kinds of such work, and that it should be adapted to the natural bent and capacity of the individual. A great many pupils have no inclination or ability for scientific work, just as various others have no capacity for music, or for mathematics, or for languages, or for administration, or for craftsmanship. All this, of course, is the merest educational com. monplace.

What I am advocating is that all should receive the elements of a liberal education, including a broad and real introduction to science in the secondary school, that for pupils of the greatest general ability specialization should be deferred to a later age than it is at present, so that general education could be carried further and a better and wider culture opened to the best growing minds. In this way a juster balance would be reached between the different aspects of human knowledge and a more secure foundation would be laid for a proper choice of occupation. Science would be placed in its proper light before the eyes of growing youth as one of the great channels through which man's creative powers can find expression, without the almost exclusive emphasis on its technological functions which is now prevalent. Most of those who chose a scientific career at any stage of their education would no doubt enter one of the great fields of the application of science to human use, both because the volume of employment in the technological field is and will continue to be much more ample, and because the qualities required in many such posts are much commoner than those necessary for the successful pursuit of pure research.

A comparatively small minority would engage in research or in teaching combined with research, as they do now, but this minority would be powerfully reinforced, in quality as well as in quantity, by drawing on hitherto untapped resources of the population. Comparatively rare as the combination of marked ability and strong inclination for research in pure science may be, there can be no doubt that it exists in many who at present have no opportunity of following their proper bent. The liberal school education I am contemplating should help to free the minds of those who follow any kind of scientific career from the distressing and harmful narrowness some of them now display. At the same time the acquirement of some knowledge of the real nature and significance of science should also help to abolish the equally distressing and harmful dislike and distrust of science among others to whom I have alluded.

Science is part, and by no means the least important part, of our cultural heritage, though it cannot, of course, satisfy the whole range of man's spiritual demands. We are often told that science alone is not enough, that its essentially mechanistic analysis of phenomena, not only the phenomena of the external world but of the mind itself as they are revealed by modern psychology, does not touch the essence of the human soul and cannot explain the highest values of which we are conscious. That I freely admit. Certainly we cannot do without literature, art and music, nor can we dispense with religion in its widest sense. What $I$ assert is that science, too, makes its own contribution to spiritual values, and that to limit its function to the material sphere is to impoverish our culture most disastrously.

The recent movement which exalts the material function of science and denies the right of pure science to an independent existence is a kind of philistinism which plays into the hands of those who dislike and distrust science and are only willing to concede its material services. One of the leaders of this movement tries to bolster up his case by rather childish misrepresentations of the motives of scientific research, suggesting that scientific curiosity is "not particularly noble", that the joy of now discovery, the delight in establishing some new fragment of objective truth, of contributing, in however small a degree, to a clearer insight into the order of Nature, are not the dominant impulses and feelings of the worker in pure science, that he is more often actuated by a desire to rise in the world, and that he will gladly turn his back on research to become an administrator. Such contentions are flatly contradicted by the experience of those actually engaged in research, who have the best opportunity of observing the dispositions and behaviour of their fellow-workers. That many scientists do in fact turn to administrative work in their later years is perfectly true. The ardent curiosity of the true investigator and his capacity to continue the strenuous though delightful mental work involved in continuous research often weaken as the mind loses its early vigour, though some minds retain them throughout mature life. Nor can we assert that the attractions of an easier life and a larger income are negligible, especially to those who are conscious of the weakening of their earlier impulses. But the existence and effectiveness of these other motives in such cases do not affect the truth that the actual motives of pure research are highly characteristic and remarkably strong and pure. The evidence is plain to all who will look at the facts, unless they wish to believe the contrary.

The main contention of this school of thought is, as we have seen, that research in science is always governed, consciously or unconsciously, by current social needs, and that we should now deliberately organize or 'plan' all research with the immediate object of continuing to satisfy those needs. That 'planning' must play a very large part in our future social and economic life I should be the last to deny. It is equally true that most technological work must be planned and that even in the realm of pure science there are problems that can only be dealt with effectively by directed teams of workers. This applies particularly though not exclusively to much explora. tory work and to preliminary surveys of wide scope. But the highest type of research, that which has been productive of the most fundamental discoveries, is essentially the work of individual minds, freely dealing with their own chosen material. That is the evidence of the whole history of science. If we desire to keep alive and vigorous the ultimate springs of our material welfare, and-not less important-to maintain and extend the place of science in our culture, we must jealously guard its freedom and its independence. 